\title{
A ESTRATÉGIA DA RESSEMIOTIZAÇÃO E O ENSINO DE LEITURA: CONTRIBUIÇÕES PARA A FORMAÇÃO DE PROFESSORES
}

\author{
THE STRATEGY OF RESEMANTIZATION AND TEACHING OF \\ READING: CONTRIBUTIONS TO TEACHER'S FORMATION
}

\author{
Helena Maria Ferreira ${ }^{1}$
}

\begin{abstract}
Resumo
Com a disseminação das tecnologias digitais e das interações via Internet, a atividade de leitura assume novas configurações. Nesse sentido, problematizar o processo de ensinoaprendizagem da leitura, articulando-o com o uso de tecnologias, configura-se como uma tarefa complexa, dada a necessidade de considerar várias questões que estão implicadas nas práticas sociais de linguagem. Assim, o objetivo deste trabalho é analisar os procedimentos de ressemiotização utilizados por alunos de Ensino Fundamental, em uma atividade de leitura/produção de fábulas, em suporte textual que congrega diferentes semioses. Para a consecução do trabalho, apresento alguns conceitos basilares para a questão estudada. Além disso, busco discutir a temática do ensino da leitura em suportes digitais. Por fim, analiso os procedimentos utilizados pelos alunos em uma atividade de produção de texto. A partir da análise empreendida, pude observar que a alteração do suporte possibilitou a exploração de imagens, sons, palavras, entonação, articulação das imagens etc, além do enfrentamento em relação ao manuseio de recursos tecnológicos. Essas situações, (re)significadas pelos alunos, representam possibilidades para a ampliação de habilidades relacionadas aos multiletramentos. Desse modo, considero que a formação docente deve estar assentada em orientação teórico-metodológica para o trabalho com a leitura em sala de aula, para propiciar a adoção de pedagogias linguísticas capazes de formar um leitor proficiente, de modo a atender às várias demandas de leitura trazidas pelas tecnologias digitais.
\end{abstract}

Palavras-chave: Ressemiotização. Leitura. Multimodalidade. (Multi)letramentos. Formação de professores.

\begin{abstract}
With the spread of digital technologies and Internet interactions, the reading activity takes on new configurations. In this sense, problematizing the teaching-learning process of reading, articulating it with the use of technologies, is a complex task, given the need to consider several issues that are implicated in the social practices of language. Thus, the objective of this work is to analyze the resemiotization procedures used by elementary school students, in a reading / production activity of fables, in textual support that congregates different semioses. For the accomplishment of the work, I present some basic concepts for the studied question. In addition, I try to discuss the theme of teaching reading on digital media. Finally, I analyze the procedures used by students in a text production activity. From the analysis undertaken, I could observe that the alteration of the support allowed the exploration of
\end{abstract}

\footnotetext{
${ }^{1}$ Universidade Federal de Lavras, Lavras, MG, Brasil. E-mail: helenaferreira@ del.ufla.br
} 


\section{OO DEVIR EDUCAÇÃO}

ISSN: 2526-849X

images, sounds, words, intonation, articulation of the images etc, as well as the confrontation in relation to the handling of technological resources. These situations, (re) signified by the students, represent possibilities for the expansion of abilities related to multiletramentos. Thus, I believe that teacher's formation should be based on theoretical and methodological orientation to work with reading in the classroom, to foster the adoption of linguistic pedagogies capable of forming a proficient reader, in order to meet the various demands of reading brought by digital technologies.

Keywords: Resemantization. Reading. Multimodality. (Multi)literacies. Teacher's formation.

\section{Introdução}

A atividade de pesquisa a que eu tenho me dedicado ao longo desses cinco últimos anos, centra-se na discussão sobre a leitura e a produção de textos em múltiplos contextos. Esse tema tem me levado a construir uma reflexão teórica sobre o processo de formação de professores e sobre as demandas de aprendizagem dos alunos de Educação Básica. Nesse sentido, destaco que o foco deste trabalho é a leitura mediada por tecnologias. No entanto, essa prática será tratada de modo articulação à produção de textos, de modo a contemplar os processos interativos da ação de ensinar e de aprender.

Com a disseminação das tecnologias digitais, a leitura, concebida como uma prática social, passa a ser utilizada para dinamizar diferentes tipos de interações (profissionais, acadêmicas, pessoais, comerciais etc), diferentemente de momentos anteriores em que havia o predomínio de textos impressos em papel. Essa tendência traz implicações para a instauração de uma nova concepção de leitura e, consequentemente, impõe novas demandas para a formação de leitores. O ensino na contemporaneidade passa ser dimensionado em uma perspectiva dos multiletramentos. Essa perspectiva contempla tanto a multiplicidade cultural existente em nossa sociedade quanto à semiótica de constituição dos textos (ROJO, MOURA, 2012), que, na sociedade da informação, conjugam, recorrentemente, palavras, imagens, sons, movimentos, cores, hiperlinks, diagramação, linhas, molduras, formatos e tamanhos de letras etc. Partindo do pressuposto de que a leitura nesse contexto impõe novos modos de ler um texto e exige novas habilidades para a produção de sentidos, enfim, novas interações considero que discussões sobre o ato de ler em suportes digitais assumem relevância acadêmica e social.

No entanto, problematizar o processo de ensino-aprendizagem da leitura, articulando-o com o uso de tecnologias não é uma tarefa simples, pois o ato de ler, per si, já se reveste de 


\section{Q DEVIR EDUCAÇÃO}

ISSN: 2526-849X

complexidade, dada a necessidade de considerar várias questões que estão implicadas nas práticas de linguagem, tais como: as condições de produção/recepção dos textos/discursos, os gêneros textuais/discursivos, os usos que os diferentes sujeitos fazem da linguagem nas diversas situações sociocomunicativas, estratégias a serem mobilizadas, tipos de leitor, tipos de leitura, suportes de textos etc.

Assim, neste trabalho, proponho-me a analisar os procedimentos de ressemiotização utilizados por alunos de Ensino Fundamental, em uma atividade de leitura/produção de fábulas, em suporte textual diferente. De acordo com Marcuschi (2003), os suportes textuais exercem influência nos modos de leitura, pois, dependendo do local/ambiente em que o texto foi publicado, a relação do leitor com o texto será diferente, pois o leitor não realiza a leitura da mesma forma em suportes diferentes. Nesse sentido, o autor supracitado adverte que não se deve ter uma visão reducionista do suporte, uma vez que as relações com ele são diversas e isso implica a mobilização de habilidades de leitura de novos gêneros textuais/discursivos. Além disso, acrescento que os suportes, muitas vezes, exigem alterações dos usos da linguagem e dos processos linguísticos, textuais e discursivos.

De acordo com Marcuschi (2003),

o suporte é um portador do texto, mas não no sentido de um meio de transporte ou veículo, nem como um suporte estático e sim como um locus no qual o texto se fixa e que tem repercussão sobre o gênero que suporta. [...] um locus físico ou virtual com formato específico que serve de base ou ambiente de fixação do gênero materializado como textos. (p. 7-8).

Desse modo, considero que a leitura em suporte digital gera a necessidade de se analisar os recursos/modos constitutivos de um texto, uma vez que são indiciadores de sentidos. Nesse contexto, o leitor deverá considerar as formas de organização das informações por partes (links, colunas, boxes etc) e a tendência de se integrar outras modalidades expressivas ao texto verbal escrito (imagens, sons, cores, diagramação) para o processo de produção dos sentidos, ou seja, "os recursos digitais permitem importar e integrar em um mesmo texto novos modos de expressão que foram socialmente construídos de forma paralela no contextos das diferentes mídias” (MANOVICH, 2001 apud BRAGA, RICARTE, 2005, p. 60).

Para compor a discussão, levanto alguns questionamentos acerca do ensino da leitura mediado por tecnologias digitais e, em seguida, descrevo uma atividade desenvolvida no âmbito do Programa Institucional de Bolsas de Iniciação à Docência (PIBID), pelo subprojeto

Revista Devir Educação, Lavras, vol.2, n.1, p.37-54, jan./jun., 2018. 


\title{
Q DEVIR EDUCAÇÃO
}

ISSN: 2526-849X

de Língua Portuguesa, que contemplou a leitura/produção do gênero fábula, por meio da exploração de suportes diferentes. A referida atividade foi desenvolvida na escola E.E. Cristiano de Souza, do município de Lavras, em uma turma de ensino fundamental.

Espero que o trabalho proposta possa contribuir para uma reflexão sobre o uso de tecnologias em sala de aula, uma vez que, reiteradamente, são constatadas inúmeras dificuldades para a implementação de práticas de leitura mediadas por tecnologias, em função da precária realidade das escolas.

\section{Ensino da leitura mediado por tecnologias}

Ao discorrer sobre o ensino da leitura mediado por tecnologias na escola, considero necessário pontuar quatro questões que elenco como essenciais para uma discussão sobre o ato de ler na contemporaneidade.

A primeira questão que destaco relaciona-se à concepção de leitura que fundamenta a pedagogia linguística. Segundo os Parâmetros Curriculares Nacionais - Língua Portuguesa (BRASIL, 1997, p.54):

\begin{abstract}
A leitura na escola tem sido, fundamentalmente, um objeto de ensino. Para que possa constituir também objeto de aprendizagem, é necessário que faça sentido para o aluno, isto é, a atividade de leitura deve responder do seu ponto de vista, a objetivos de realização imediata (...). Para tornar os alunos bons leitores - para desenvolver, muito mais do que a capacidade de ler, o gosto e o compromisso com a leitura -, a escola terá de mobilizá-los internamente, pois aprender a ler (e também ler para aprender) requer esforço. Precisará fazê-los achar que a leitura é algo interessante e desafiador, algo que, conquistado plenamente, dará autonomia e independência. Precisará torná-los confiantes, condição para poder se desafiar a "aprender fazendo". Uma prática de leitura que não desperte e cultive o desejo de ler não é uma prática pedagógica eficiente.
\end{abstract}

A partir dessa afirmação, posso considerar que a concepção de leitura, que sustenta uma abordagem multissemiótica e que propicia a aquisição e/ou o aperfeiçoamento de habilidades relacionadas aos multiletramentos, deve estar assentada em uma perspectiva interacionista, visto que o ato de ler um processo ativo e dinâmico, pois o "texto tem um potencial de evocar significado, mas não tem significado em si mesmo" (MOOR; CASTRO; COSTA, 2001, p. 160). Nessa direção, a leitura é compreendida como um ato dialógico e interlocutivo, que abarca questões sociais (históricas e ideológicas) e individuais (experiências, conhecimentos

Revista Devir Educação, Lavras, vol.2, n.1, p.37-54, jan./jun., 2018. 


\section{QO DEVIR EDUCAÇÃO}

ISSN: 2526-849X

prévios, formação familiar, escolar e cultural de cada leitor, crenças, valores). Assim, é preciso considerar que "o lugar mesmo da interação [...] é o texto cujo sentido não está lá, mas é construído considerando-se, para tanto, as sinalizações textuais dadas pelo autor e os conhecimentos do leitor." (KOCH; ELIAS, 2010, p. 12). Não se trata de uma atividade de mera decodificação, ou seja, no diálogo com o texto "ocupa simultaneamente uma posição ativa e responsiva: concorda ou discorda dele (total ou parcialmente) completa-o, aplica-o, prepara para usá-lo, etc. [...] Toda compreensão é prenhe de resposta" (BAKHTIN, 2003, p. 271). Essa concepção de leitura permitirá o encaminhamento do ato de ler de modo a considerar a interação efetiva entre autor-texto-leitor-contexto social.

Articulada à discussão sobre concepção de leitura, a segunda questão que destaco relaciona-se à formação de professores. Reconhecendo o papel da escola para a formação de leitores proficientes e de cidadãos críticos, considero que a orientação teórico-metodológica do professor irá influenciar, sobremaneira, na escolha dos materiais didáticos, na preparação de atividades didáticas, no encaminhamento das práticas de leitura, enfim, na qualidade das interações dinamizadas durante a leitura de textos para a formação de sujeitos com proficiência leitora.

Discorrendo sobre o ensino de línguas, de um modo geral, Tunes (2016, p. 125) afirma que "há muito se vem falando sobre um ensino que seja significativo aos sujeitos nele implicados, mas o que vemos até o presente momento são reproduções de costumes antigos e práticas esvaziadas de sentido." Corroboro a asserção defendida pela autora, mas não posso deixar de sinalizar avanços substanciais nas práticas de ensino de línguas, a partir da instauração de pedagogias de gêneros, do deslocamento de metodologias tradicionais (ensino de conteúdos) para metodologias de cunho interacionista (trabalho por habilidades, consideração do contexto de aprendizagem e uso de tecnologias em sala de aula). Nesse sentido, considero necessário para que o processo ensino-aprendizagem seja proficiente, as práticas pedagógicas devem estar assentadas em teorias linguísticas, no viés teóricometodológico em que a leitura seja concebida como prática social imbricada a outras práticas, como oralidade, produção de textos escritos, análises linguísticas.

Sobre a formação de professores para o uso de tecnologias em sala de aula, Freitas (2010, p. 5) pontua que

se o desejável é que os professores integrem computador-internet à prática profissional, transformando-a para melhor inseri-la no contexto de nossa sociedade marcada pelo digital, é preciso ir muito além. Os professores

Revista Devir Educação, Lavras, vol.2, n.1, p.37-54, jan./jun., 2018. 


\section{DO DEVIR EDUCAÇÃO}

ISSN: 2526-849X

precisam conhecer os gêneros discursivos e linguagens digitais que são usados pelos alunos, para integrá-los, de forma criativa e construtiva, ao cotidiano escolar. Quando digo integrar é porque o que se quer não é o abandono das práticas já existentes, que são produtivas e necessárias, mas que a elas se acrescente o novo. Precisamos, portanto, de professores e alunos que sejam letrados digitais, isto é, professores e alunos que se apropriam crítica e criativamente da tecnologia, dando-lhe significados e funções, em vez de consumi-la passivamente. O esperado é que o letramento digital seja compreendido para além de um uso meramente instrumental.

Nessa perspectiva, reitero que, com a democratização do acesso à Internet, as pessoas estão imersas em diferentes tecnologias e isso faz com que os modos de leitura/escrita sejam redimensionados, demandando novas metodologias e estratégias de ensino por parte das instituições escolares. Segundo Canclini (2005, p. 237), "a conjugação de telas de televisão, computadores e videogames está familiarizando as novas gerações com os modos digitais de experimentar o mundo, com os estilos e ritmos de inovação próprios destas redes."

Esse contato com essas redes possibilita o desenvolvimento de habilidades - intituladas de multiletramentos - que dizem respeito à capacidade de operar, eficazmente e criticamente, ferramentas utilizadas nos processos de constituição dos textos em contextos hipermidiáticos. Isso inclui, além do conhecimento funcional sobre o uso da tecnologia e de suas potencialidades, um conhecimento crítico desse uso. Tais ferramentas estão relacionadas à escrita manual e/ou impressa, ao áudio, ao vídeo, ao tratamento da imagem, à edição e à diagramação. (ROJO; MOURA, 2012). Assim, os multiletramentos estão relacionados à mobilização de conhecimentos relacionados às diferentes modalidades (oral, escrita, imagens) "para expressar-se e partilhar informações, experiências, ideias e sentimentos em diferentes contextos e, com eles, produzir sentidos que levem ao entendimento mútuo". (p. 21). Isso implica em utilizar tecnologias digitais "de forma crítica, significativa, reflexiva e ética nas diversas práticas do cotidiano (incluindo as escolares) ao se comunicar, acessar e disseminar informações, produzir conhecimentos e resolver problemas.” (BRASIL, BNCC, 2017, p. 18)

Para uma leitura proficiente, é preciso considerar a multiplicidade de elementos constitutivos dos textos, as potencialidades dos recursos verbais e não verbais para a construção dos sentidos. Além do signo linguístico, há outros elementos sígnicos em jogo: ilustrações, cores, sons, movimentos, silêncios etc. Nessa perspectiva, o texto é um evento comunicativo em que podem atuar várias linguagens (verbal, visual, sonora etc.).

A terceira questão a ser destacada é a exploração da articulação entre as diferentes linguagens, o que constitui a multimodalidade, entendida aqui como a conjugação de 
diferentes modos semióticos: a escrita, a fala e a imagem. Esse fenômeno abarca a multissemiose, ou seja, distintas formas e modos de representação utilizados na construção linguística de uma dada mensagem, tais como: palavras, imagens cores, formatos, marcas/ traços tipográficos, disposição da grafia, gestos, padrões de entonação, olhares etc. (Dionísio, 2005). A leitura, nessa ótica, se revela na descentralização da linguagem verbal como favorecedora da construção do sentido, já que outros recursos se fazem presentes no processo de organização das informações. Além disso, essa tendência demanda também um novo olhar sobre os tênues limites entre os papéis da linguagem verbal, da imagem, do suporte, do layout etc. Assim, é relevante ressaltar que um texto pode se materializar por meio da linguagem escrita, oral e/ou imagética, bem como da articulação/ integração dessas modalidades. (GOMES, 2010).

Discorrendo sobre essa questão, Kress e van Leuween (2006) apontam a necessidade de práticas pedagógicas que promovam o aperfeiçoamento das habilidades de questionar, interpretar e criticar os recursos multissemióticos. Para os autores citados, a multimodalidade contempla um texto em seu todo significativo, ou seja, na inter-relação entre seus diferentes elementos constituintes. Assim, o empoderamento semiótico depende da compreensão das diferentes semioses presentes em cada gênero e deve partir dos seguintes pressupostos: a) as imagens visuais podem ser lidas como um texto; b) a multiplicidade de significados dos textos multimodais deve estar pautada nos seus contextos sociais; c) as imagens visuais, como a linguagem e todos os modos semióticos, são socialmente construídas.

Em suma, o processo de leitura, em uma sociedade multimídia, não deve ficar restrito aos elementos verbais, ou seja, os elementos visuais (imagens, sons, movimentos, cores, diagramação, formatos e destaques) devem ser considerados como elementos constitutivos que contribuirão, de forma significativa, para formar o ato comunicativo. Assim, os papéis assumidos por esses elementos devem ser levados em conta, conjuntamente. Nesse viés, podemos considerar que uma análise multimodal/ multissemiótica se faz necessária, pois as diferentes semioses transformam-se em referências diretas ou indiretas da realidade física e social, recortam o mundo, evidenciam intencionalidades, legitimam argumentos e fatos.

Além disso, devem ser considerados também o contexto de produção (quem produziu, quando, onde, por que, para quem, para circular em que veículo, em qual suporte etc), o conteúdo temático (o que o texto diz relacionado com o autor, com o momento histórico e com seus possíveis interlocutores), a construção composicional (o gênero que organiza o texto

Revista Devir Educação, Lavras, vol.2, n.1, p.37-54, jan./jun., 2018. 


\section{Q DEVIR EDUCAÇÃO}

ISSN: 2526-849X

e sua esfera social de produção) e o estilo (seleção lexical, estilo do autor, marcas linguísticas, forma de organização do enunciado) (HOPE, COSTA-HÜBES, 2013, p. 9).

Por fim, destaco a quarta questão, que diz respeito às operações feitas pelos alunos no processo de leitura/produção de textos na exploração dos suportes diferentes. A essas operações nomeamos de ressemiotização, que se refere a "como a produção do sentido muda de contexto para contexto, de prática para prática, ou de um estágio da prática para outro, servindo a interesses particulares" (IEDEMA, 2003, apud SCHEIFER, 2014, p. 123). Nesse processo, há um deslocamento de sentido de um modo semiótico a outro modo semiótico diferente, sendo que cada semiótica terá restrições e permissões específicas (o que se pode fazer com a língua não pode ser feito com a representação visual e vice-versa). Ao alterar o suporte textual, o autor opera de modo diferenciado e faz adequações, pois a ressemiotização não produz similitude, mas representa "um conjunto de múltiplos canais de direções" (IEDEMA, 2003, apud SCHEIFER, 2014, p. 124), por isso produz discrepâncias. Esse processo promove um deslocamento da noção de letramento como representação do espaço (ou espaço concebido) para uma noção de letramento como espaço representacional (ou vivido) (SCHEIFER, 2014).

A partir desses conceitos, posso assegurar que compreender/produzir as construções sígnicas articuladas às questões contextuais, aos gêneros textuais/discursivos e aos suportes textuais, interagir com elas, produzir sentidos a partir delas e por meio delas, demanda uma mobilização de competências e habilidades distintas por parte do sujeito-leitor/produtor. Desse modo, a consideração das questões propostas para discussão se configuram como uma possibilidade de se repensar o ensino da leitura mediado por tecnologias, uma vez que o suporte digital possui especificidades que demandam novas formas de ler e de interagir com os textos.

\section{Descrição e análise de atividades de intervenção}

O projeto, intitulado "O incrível universo dos gêneros textuais", foi idealizado por uma professora supervisora, com a colaboração dos bolsistas do PIBID, sendo desenvolvido em uma escola pública, com alunos de $6^{\circ}$ ao $9^{\circ}$ ano do Ensino Fundamental, sob a minha coordenação. Em função dos limites deste trabalho, selecionei, para descrição e para análise 


\section{Q DEVIR EDUCAÇÃO}

ISSN: 2526-849X

apenas as atividades realizadas na Oficina de Leitura e Produção de Textos, no subprojeto: "Audiolivro de Fábulas".

A oficina teve por objetivo trabalhar o gênero fábula com os alunos, com vistas a explorar os diferentes recursos constitutivos dos textos, estimular o gosto pela leitura, despertar a criatividade, bem como estimular o interesse pela produção de textos.

Inicialmente, foi feito um levantamento acerca das fábulas já lidas/ouvidas pelos alunos. Foi feito um estudo diagnóstico dos conhecimentos prévios sobre o gênero fábula. A seguir, foi realizada um conversa dialogada com os alunos sobre as fábulas, com informações sistematizadas sobre origem, funções sociais assumidas ao longo dos anos e características do gênero: estrutura composicional, objetivo comunicativo, estilo de linguagem. Foi proposta uma pesquisa, na qual os alunos deveriam organizar as informações aprendidas sobre as fábulas e inserir um exemplo desse gênero textual.

Posteriormente, foram sorteados para cada grupo de aluno: uma moral, um cenário e dois personagens para que produzissem uma fábula. A partir desses elementos, cada grupo produziu o texto. Dando sequência, foi realizada uma discussão sobre suportes textuais, recursos semióticos (imagens, cores, posicionamento, enquadramento, sons, falas, ritmo, diagramação etc). Em seguida, foi solicitado aos alunos para que ilustrassem o texto produzido por partes e que organizassem uma forma de apresentação para os colegas. Dada a quantidade de textos produzidos, considerando o número de alunos das turmas em que o projeto foi aplicado, optei por selecionar apenas uma produção para análise. O estudo do texto selecionado não se pautou em uma perspectiva da análise literária, mas foi fundamentada na abordagem da Teoria dos Gêneros Textuais/Discursivos, da Teoria da Multimodalidade e da Gramática do Design Visual (GDV).

O texto analisado pode ser encontrado no link: https://youtu.be/pTeBV3Oq8mw e se intitula "A baleia e o cachorro". O grupo de alunos fez opção pelo uso de um texto multimodal (fala, escrita, sons e imagens).

Para a análise, foram eleitos dois indicadores. O primeiro diz respeito ao atendimento ao gênero textual.

De acordo com Bagno (2006, p. 51)

A fábula é um gênero literário muito antigo que se encontra em praticamente todas as culturas humanas e em todos os períodos históricos. Este caráter universal da fábula se deve, sem dúvida, à sua ligação muito íntima com a sabedoria popular. De fato, a fábula é uma pequena narrativa que serve para

Revista Devir Educação, Lavras, vol.2, n.1, p.37-54, jan./jun., 2018. 


\section{DO DEVIR EDUCAÇÃO}

ISSN: 2526-849X

ilustrar algum vício ou alguma virtude, e termina, invariavelmente, com uma lição de moral. Até hoje, quando terminamos de contar um caso ou algum acontecimento interessante ou curioso, é comum anunciarmos o final de nossa narrativa dizendo: "moral da história"... Pois é justamente da tradição das fábulas que nos vem esse hábito de querer buscar uma explicação ou uma causa para as coisas que acontecem em nossa vida ou na vida dos outros, ou de tentar tirar delas, algum ensinamento útil, alguma lição prática.

Considerando a fábula produzida pelos alunos, é possível constatar que o texto atende às características do gênero: uma narrativa curta, que ilustra uma virtude e um falha humanas e que termina com uma moral.

Outro ponto a ser destacado é que "a grande maioria das fábulas tem como personagens animais ou criaturas imaginárias (criaturas fabulosas), que representam, de forma alegórica, os traços de caráter (negativos e positivos) dos seres humanos” (BAGNO, 2006, p. 51). No caso analisado, os alunos utilizaram, adequadamente, dos dois animais distribuídos ao grupo e conseguiram antropomorfizar os personagens, atentando-se, assim, com a função social da fábula, passar um ensinamento. Assim, o seguinte esquema pode ser apresentado:

$\Rightarrow$ contexto de produção (quem produziu, quando, onde, por que, para quem, para circular em que veículo, em qual suporte etc) $=>$ os alunos produziram uma fábula em papel e, depois, transcodificaram-na para o suporte digital, em ambiente de sala de aula, para cumprirem uma atividade escolar e para socializarem a produção com os colegas e com os professores, com o propósito de demonstrar os conhecimentos sobre o gênero fábula.

$\Rightarrow$ conteúdo temático (o que o texto diz está relacionado com o autor, com o momento histórico e com seus possíveis interlocutores): os alunos utilizaram de uma temática atual - relacionamento entre amigos.

$\Rightarrow$ construção composicional (o gênero que organiza o texto e sua esfera social de produção): os alunos produziram um texto narrativo, com uma moral no final.

$\Rightarrow$ estilo (seleção lexical, estilo do autor, marcas linguísticas, forma de organização do enunciado): os alunos adotaram um estilo de linguagem simples, como é constituída a fábula, com estrutura narrativa, com vocabulário acessível, com verbos no passado.

O segundo indicador selecionado para análise da produção de texto dos alunos diz respeito uso de recursos multimodais/multissemióticos.

Revista Devir Educação, Lavras, vol.2, n.1, p.37-54, jan./jun., 2018. 


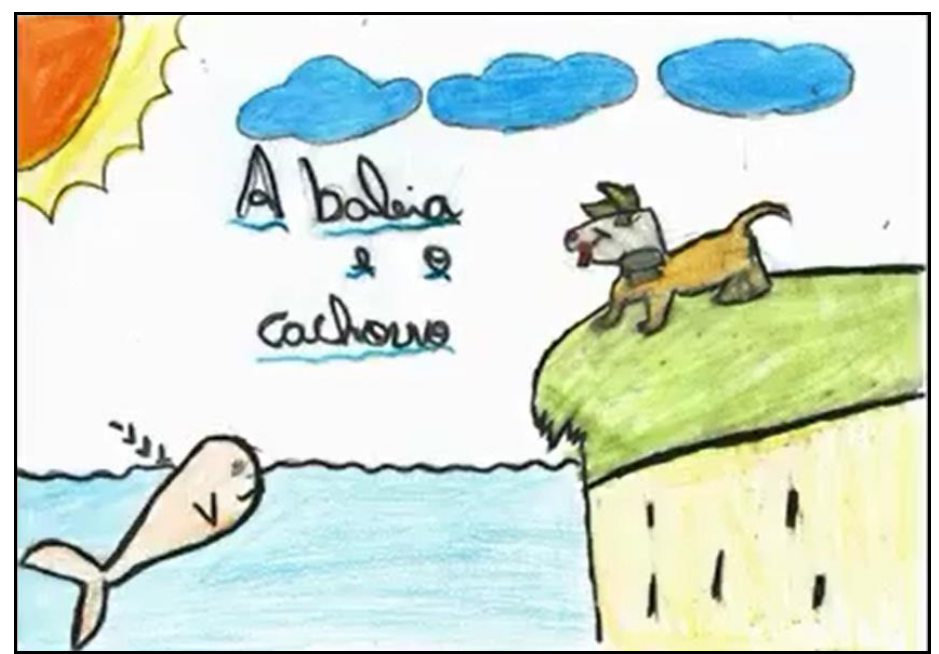

Figura 1: Tela inicial da história produzida pelos alunos

Fonte: https://youtu.be/pTeBV3Oq8mw

Na figura 1, é possível destacar escolhas que influenciam no processo de produção de sentidos: a) título: em posição central para destacar a história apresentada; b) cenário: com cores naturais para dar uma impressão realística dos fatos narrados; c) personagens: apresentação dos dois, simultaneamente, para dar uma ideia geral do conteúdo da história; d) articulação com o texto verbal, o que evidencia a pertinência das informações; e) posicionamento dos personagens: a inserção do cachorro do lado direito representa, segundo a Gramática do Design Visual, proposta por Kress e Van Leuween (2006), retrata a relevância do personagem para a trama, instaurando-se como a informação mais importante, no caso, assumindo a função de sujeito-agente do comportamento abordado pela fábula, a baleia se coloca como coadjuvante. 


\section{QO DEVIR EDUCAÇÃO}

ISSN: 2526-849X

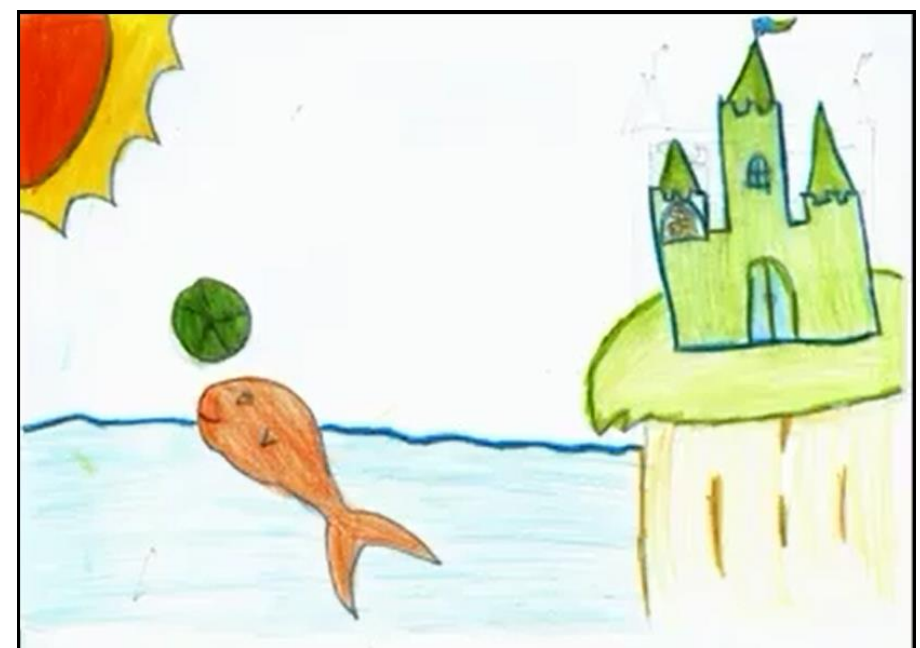

Figura 2: Tela 2 da história produzida pelos alunos

Fonte: https://youtu.be/pTeBV3Oq8mw

Na figura 2, destaco: a) manutenção do cenário com poucas modificações: o que substitui os mecanismos de coesão próprios do texto verbal; b) personagens em ação: a baleia brincando de bola e o cachorro em casa evidenciam ações reais, o que sugere características humanas aos personagens (necessários para a construção da fábula); c) articulação entre texto verbal e texto não verbal: o que orienta a compreensão do texto produzido, pois sem o texto verbal, o entendimento da história seria seriamente comprometido; d) cores fortes do sol e das nuvens: representar a temporalidade da cena; ou seja, o fato ocorreu durante o dia.

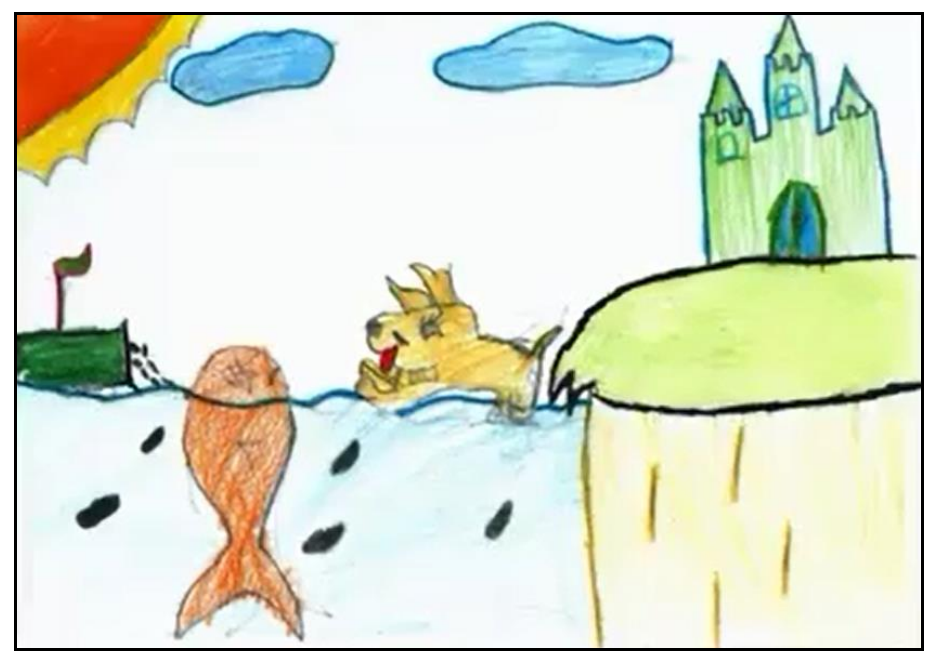

Figura 3: Tela 3 da história produzida pelos alunos

Fonte: https://youtu.be/pTeBV3Oq8mw 


\section{Q DEVIR EDUCAÇÃO}

ISSN: 2526-849X

Na figura 3, destaco: a) manutenção do cenário com poucas modificações: o que substitui os mecanismos de coesão próprios do texto verbal; b) cachorro sem coleira: adequação para a entrada na água; c) presença de respingos de petróleo no mar: o petróleo em gotas (não uma mancha escura) representa uma quantidade suficiente para causar o desmaio da baleia. A presença de uma quantidade maior poderia sugerir a morte da personagem; d) solidariedade por parte do cachorro: representa uma preparação para a ação de retribuição da gentileza por parte da baleia, essa questão é cara para a construção de uma fábula; e) deslocamento do cachorro para a água: indicação de ajuda à baleia.

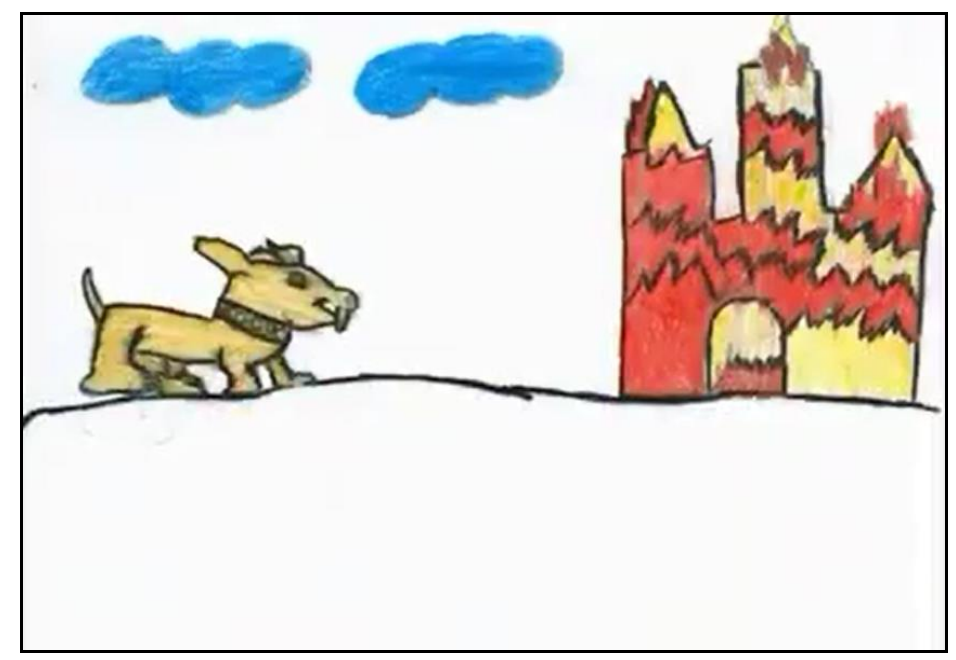

Figura 4: Tela 4 da história produzida pelos alunos

Fonte: https://youtu.be/pTeBV3Oq8mw

Na figura 4, destaco: a) enquadramento de cena: a delimitação da imagem no cachorro e no castelo evidencia a importância desse acontecimento para a composição da história; b) uso de cores vermelha e amarela: trata-se de um recurso para representar o fogo e a gravidade da situação; c) manutenção das nuvens: refere-se à busca de emprestar veracidade à realidade descrita; d) fundo branco: destaque para a cena do incêndio do castelo; e) articulação entre texto verbal e texto não verbal: o que orienta a compreensão do texto produzido. 


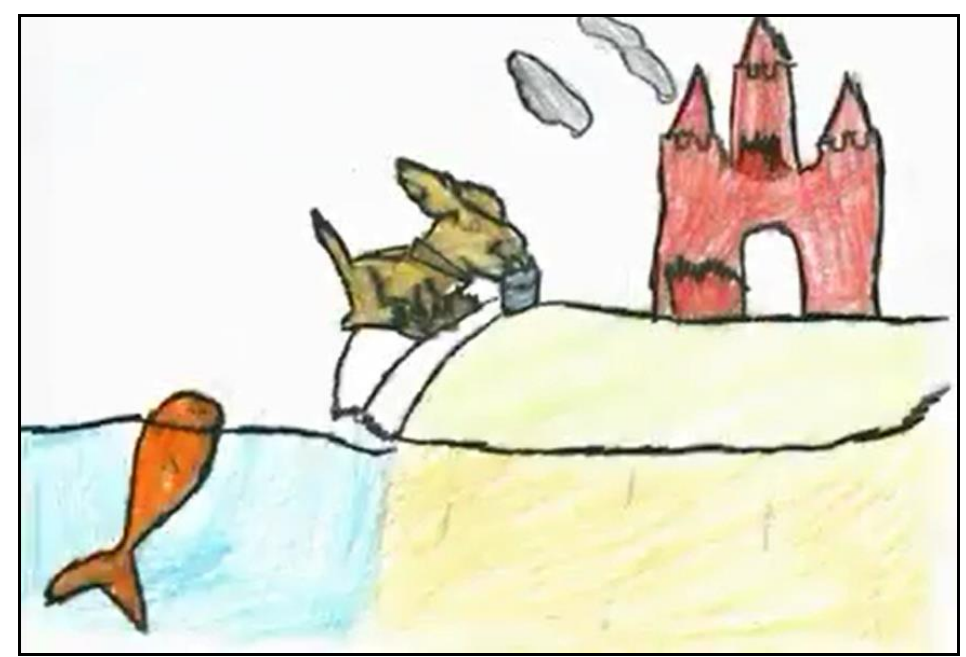

Figura 5: Tela 5 da história produzida pelos alunos

Fonte: https://youtu.be/pTeBV3Oq8mw

Na figura 5, destaco: a) manutenção do cenário sem nuvens e sem sol: parece destacar a ação/comportamento dos personagens, questão mais importante nesse momento da narração; b) inserção de um balde na cena: indica o modo como o cachorro conseguir extinguir o incêndio em seu castelo; c) cor do castelo: a vermelha indicia o incêndio; d) elementos indicativos de fumaça: para indiciar que o fogo foi extinguido; e) cor verde (quase apagada) no gramado: para enfatizar a cena do incêndio.

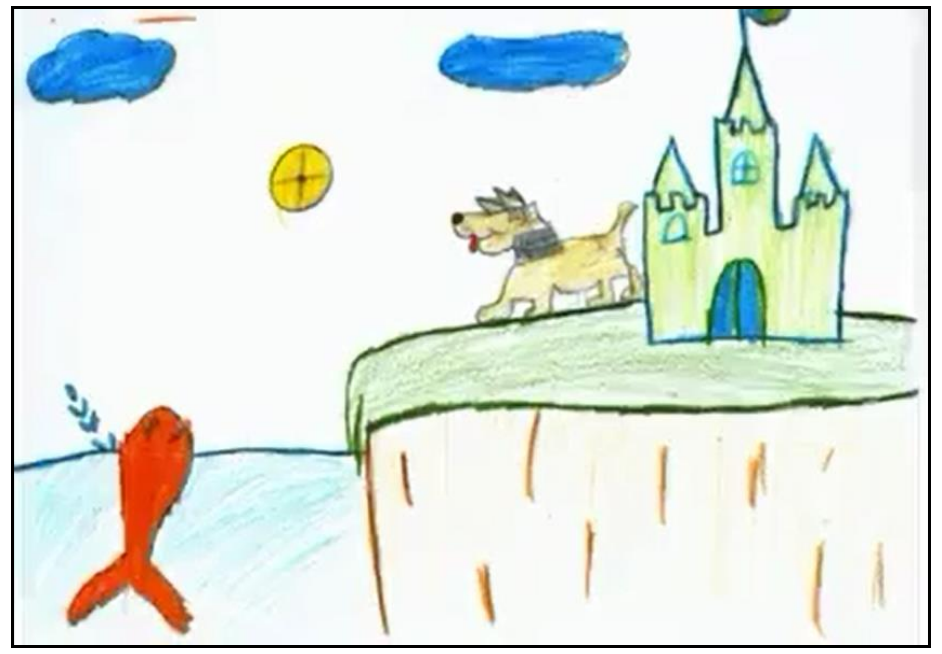

Figura 6: Tela final da história produzida pelos alunos

Fonte: https://youtu.be/pTeBV3Oq8mw

Na figura 6, destaco: a) retomada do cenário inicial (com poucas modificações: indica a normalidade da situação; b) presença da bola em posição diferente: indicia que os 


\section{Q DEVIR EDUCAÇÃO}

ISSN: 2526-849X

personagens estão brincando com o objeto, retomando o relacionamento amistoso; c) uso de cores: evidencia que as situações inesperadas presentes na complicação da narração foram resolvidas/superadas; d) cor vermelha da personagem baleia: indicativo de alegria; e) articulação entre texto verbal e texto não verbal: o que orienta o leitor para a finalização da fábula.

Além dos elementos destacados, destaco a música de fundo, ao final do vídeo, que empresta ritmo ao texto e que é bastante comum em textos em movimento. Por fim, merece destaque que o texto-base que foi verbovisualizado apresentou coerência nas escolhas feitas pelos autores. Os recursos multimodais apresentaram-se de modo articulado, o que evidencia o domínio de habilidades relacionadas aos multiletramentos. Acresce-se também a questão da entonação, presente na narração da aluna, que também empresta qualidade à construção da fábula em suporte digital. O processo de ressemiotização do texto verbal escrito para o texto multimodal representou uma estratégia importante para o redimensionamento da noção de produção de textos como produto pronto e acabado. A articulação entre texto verbal (escrito e lido) e não verbal permitiu a exploração conjunta dos vários elementos que constituem os gêneros textuais que integram as práticas sociais.

\section{Considerações finais}

Ao encerrar a discussão proposta neste estudo, reitero a afirmação feita na introdução, qual seja, a de que ensinar a ler é uma atividade complexa. Nessa direção, a partir da reflexão aqui empreendida, posso destacar que ensinar leitura demanda a inserção ativa dos sujeitos nesse processo, de modo a garantir que as diferentes pistas deixadas pelos autores sejam percebidas e reorganizadas pelos leitores, de forma a construir sentidos e possibilitar interpretações.

A tarefa de analisar as atividades de leitura/produção de textos em suportes diferentes, objetivo eleito para este trabalho, representou, para mim, uma possibilidade pedagógica de acompanhar o desenvolvimento de um projeto de intervenção em uma escola pública, em que o acesso às tecnologias digitais é, notadamente, restrito e idealizado. Desse modo, constatei que o ensino da leitura mediado por tecnologias não pode estar subjugado a investimentos exponenciais, uma simples retextualização/ressemiotização (como a que descrevo aqui) representa para os alunos uma situação de ensino-aprendizagem bastante motivadora. Foi 


\section{Q DEVIR EDUCAÇÃO}

ISSN: 2526-849X

impossível não me emocionar com os olhares curiosos, com as resistências devido à timidez, com os depoimentos, com os enfrentamentos, com as improvisações, com os resultados.

A partir deste trabalho, foi possível constatar que a transposição da fábula em suporte de papel para o suporte digital incitou os alunos a explorarem a multimodalidade/multissemiose presentes na ilustração e na gravação de áudios. Para tal, foram feitas discussões sobre as representações imagéticas, que não se circuncrevem na atividade de desenho em si, mas nos efeitos de sentido pretendidos. Essas discussões desencadearam uma reflexão acerca da tradição escolar de que as imagens (desenhos) são tarefas atribuídas a alunos de anos iniciais de alfabetização. A construção imagética de um texto demanda habilidades para além de habilidades manuais, exige articulação com o texto verbal, exige uma atenção aos mecanismos de articulação (coesão) e de coerência (progressão temática), exige cuidado com cores, formatos, diagramação, formas de representação, ou seja, recursos que são indiciadores de sentido. A gravação de áudios também representou uma possibilidade ímpar de formação de leitores, pois a reflexão demandou a incorporação de uma discussão sobre variação linguística, adequação da leitura/fala aos contextos de usos e dos suportes veiculadores do texto, aos usos de fala pública, impressões causadas no leitor/ouvinte, além da tarefa de adequação do texto às modalidades escrita/falada.

Nesse sentido, corroboro a posição de Marcuschi (2003), qual seja, a de que as relações com o suporte são diversas e isso implica a mobilização de habilidades diversas de leitura. No caso analisado, a alteração do suporte possibilitou a exploração de imagens, sons, palavras, entonação, articulação das imagens etc, além do enfrentamento em relação ao manuseio de recursos tecnológicos. Essas situações, significadas pelos alunos, representam possibilidades para a ampliação de habilidades relacionadas aos multiletramentos.

Desse modo, considero que a formação docente deve estar assentada em orientação teórico-metodológica para o trabalho com a leitura em sala de aula, para propiciar a adoção de pedagogias linguísticas capazes de formar um leitor proficiente, de modo a atender às várias demandas de leitura trazidas pelas tecnologias digitais. Trabalhar com a formação de leitores na sociedade da informação exige do professor uma revisão de suas concepções de leitura, uma análise das (re)configurações dos gêneros textuais/discursivos, uma atenção às potencialidades de seus recursos/modos semióticos como elementos indiciadores de sentido e uma sensibilidade em relação ao compromisso ético de formar cidadãos críticos e proficientes no complicado/instigante exercício de interagir com textos e discursos.

Revista Devir Educação, Lavras, vol.2, n.1, p.37-54, jan./jun., 2018. 


\section{Referências}

BAKHTIN, Mikhail. Estética da criação verbal. 4. ed. São Paulo: Martins Fontes, 2003.

BAGNO, Marcos. OS. Fábulas fabulosas. In: CARVALHO, M. A. F. de; MENDONÇA, R. H. (Orgs). Práticas de leitura e escrita. Brasília: Ministério da Educação, 2006.

BRAGA, Denise Bertoli; RICARTE, Ivan Luiz Marques. Letramento na era digital: construindo sentidos através da interação com hipertextos. Revista da ANPOLL, IELUNICAMP, v. 18, p. 59-82, 2005.

BRASIL. Secretaria de Educação Fundamental. Parâmetros curriculares nacionais: primeiro e segundo ciclos do ensino fundamental. Secretaria de Educação Fundamental. Brasília: MEC/SEF, 1997.

BRASIL. Ministério da Educação. Base Nacional Curricular Comum do Ensino Básico. 2017 Disponível em: <http://basenacionalcomum.mec.gov.br/images/BNCC_publicacao.pdf.> Acesso em 08 abr. 2017.

CANCLINI, Néstor García. Diferentes, desiguais e desconectados. Rio de Janeiro: UFRJ, 2005.

FREITAS, Maria Teresa. Letramento digital e formação de professores. Educ. rev., Belo Horizonte, v. 26, n. 3, p. 335-352, dez. 2010. Disponível em:

<http://www.scielo.br/scielo.php?script=sci_arttext\&pid=S0102-46982010000300017> Acesso em: 8 abr. 2017.

HOPPE, Márcia Cristina; COSTA-HÜBES, Terezinha da Conceição. Concepções de leitura na Educação Básica e a sua relação com a Prova Brasil. In: XI Jornada do HISTEDBR, 2013, Cascavel. Anais da XI Jornada do HISTEDBR. Cascavel - PR: Edunioeste, 2013. Disponível em:

http://www.histedbr.fe.unicamp.br/acer_histedbr/jornada/jornada11/artigos/7/artigo_simposio _7_1036_inter_marcia@hotmail.com.pdf>. Acesso em 05 abr. 2017.

KOCH, Ingedore Villaça; ELIAS, Vanda Maria. Ler e compreender: os sentidos do texto. 3.ed., 3. reimpressão. São Paulo: Contexto, 2010.

KRESS, Gunther; VAN LEEUWEN, T. Reading images: the grammar of visual design.5th. London and New York: Routledge, 2006.

MARCUSCHI, Luiz Antonio. A questão do suporte dos gêneros textuais. Recife: Ed. da UFPE; CNPq, 2003.

MOOR, Annie Marie; CASTRO,. Rafael Vetromille de; COSTA, Giordana Pozza. O ensino colaborativo na formação do professor de inglês instrumental. In: LEFFA, V. (Org.). O 


\section{OO DEVIR EDUCAÇÃO}

ISSN: 2526-849X

professor de línguas estrangeiras: construindo a profissão. Pelotas: Educat, 2001. p. 157173.

ROJO, Roxane; MOURA, Eduardo. Multiletramentos na escola. São Paulo: Parábola, 2012.

SCHEIFER, Camila Lawson. Espaço-temporalidade, ressemiotização e letramentos : um estudo sobre os movimentos de significação no terceiro espaço. Campinas, SP, Tese (doutorado) - Universidade Estadual de Campinas, IEL, 2014.

TUNES, Stefanie. Bakhtin e a ecologia linguística no ensino de língua. In: SOBRAL, A.; BOHN, H. (Org.). Dialogismo: bordas, fronteiras, imprecisões, sentidos. Pelotas: EDUCAT, 2016. 